\title{
Food intake patterns and gallbladder disease in Mexican Americans
}

\author{
Marilyn Tseng ${ }^{1, *}$, Robert F DeVellis ${ }^{2}$, Kurt R Maurer ${ }^{3}$, Meena Khare ${ }^{3}$, Lenore Kohlmeier ${ }^{1,4}$, \\ James E Everhart ${ }^{5}$ and Robert S Sandler 6 \\ 'Department of Epidemiology, University of North Carolina, Chapel Hill, NC 27599, USA: ${ }^{2}$ Department of \\ Health Behavior and Health Education, University of North Carolina, Chapel Hill, NC 27599, USA: ${ }^{3}$ National \\ Center for Health Statistics, Hyattsville, MD 20782, USA: ${ }^{4}$ Department of Nutrition, University of North Carolina, \\ Chapel Hill, NC 27599, USA: ${ }^{5}$ National Institute of Diabetes and Digestive and Kidney Diseases, Bethesda, MD \\ 20892, USA: ${ }^{6}$ Division of Digestive Diseases and Nutrition, Department of Medicine, University of North \\ Carolina, Chapel Hill, NC 27599, USA
}

Submitted 10 April 1999: Accepted 1 September 1999

\begin{abstract}
Objective: Results of previous studies on diet and gallbladder disease (GBD), defined as having gallstones or having had surgery for gallstones, have been inconsistent. This research examined patterns of food intake in Mexican Americans and their associations with GBD.

Design: Cross-sectional.

Subjects: The study population included 4641 Mexican Americans aged 20-74 years who participated in the 1988-94 third National Health and Nutrition Examination Survey (NHANES III). GBD was diagnosed by ultrasound. Food intake patterns were identified by principal components analysis based on food frequency questionnaire responses. Component scores representing the level of intake of each pattern were categorized into quartiles, and prevalence odds ratios (POR) were estimated relative to the lowest quartile along with 95\% confidence intervals (CI).

Results: There were four distinct patterns in women (vegetable, high calorie, traditional, fruit) and three in men (vegetable, high calorie, traditional). After age adjustment, none were associated with GBD in women. However, men in the third $(\mathrm{POR}=0.42,95 \% \mathrm{CI} 0.21-0.85)$ and fourth (POR $=0.53,95 \% \mathrm{CI} 0.28-1.01)$ quartiles of the traditional intake pattern were half as likely to have GBD as those in the lowest quartile.

Conclusions: These findings add to a growing literature suggesting dietary intake patterns can provide potentially useful and relevant information on diet-disease associations. Nevertheless, methods to do so require further development and validation.
\end{abstract}

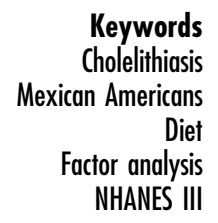

Gallstones or gall bladder disease (GBD) is an exceptionally common source of morbidity worldwide, particularly among women. Prevalence of the disease varies substantially across geographic and ethnic groups, and crude prevalence is as high as $20 \%$ in some European ${ }^{1-3}$ and native and Mexican American ${ }^{4-6}$ female populations. Diet has long been of interest as a risk factor for gallstones. Numerous mechanisms have been proposed by which various dietary factors may influence the formation of gallstones, including effects on cholesterol metabolism, bile lithogenicity and nucleation time ${ }^{7}$.

Ecological studies have noted a rise in the prevalence of gallstones with more western diets, characterized by a higher intake of fat and refined carbohydrate but a lower intake of fibre ${ }^{8-10}$. Overall, findings from other observational nutritional epidemiological studies do not provide strong evidence for an association with caloric intake or intake of fatty acids or cholesterol ${ }^{11-19}$, but they offer evidence of a positive association with simple sugars ${ }^{12,14,15,19}$ and inverse associations with fibre ${ }^{12,14,17-21}$ and alcohol $5,12,14,16,19,20,22-31$. While epidemiological and aetiological studies suggest a role for specific nutrients, however, it is unclear how these findings relate to actual dietary practice, since nutrients are consumed in complex combinations. While perhaps useful for aetiological understanding, such findings do not directly address the issue of whether or not certain characteristic combinations of foods or food intake patterns are associated with disease risk.

The objective of this research was to determine if certain food intake patterns are associated with disease. Our goal was not to elucidate aetiology, but to quantify the 
aggregate risk associated with particular combinations of foods ${ }^{32}$. We used data from NHANES III ${ }^{33,34}$ to examine the association between food intake patterns and GBD in Mexican Americans. We chose to focus on Mexican Americans because prevalence of the disease is high, particularly in Mexican American women; based on data from NHANES III, age-adjusted prevalence in this population is $8.9 \%$ in men and $26.7 \%$ in women, compared to $8.6 \%$ and $16.6 \%$ in non-Hispanic white and $5.3 \%$ and $13.9 \%$ in African American men and women, respectively ${ }^{35}$. We used NHANES III data to: (i) identify food patterns in Mexican American women and men using principal components analysis; and (ii) examine the associations of these patterns of intake with GBD.

\section{Materials and methods}

\section{Study population}

NHANES III, a cross-sectional survey conducted from 1988 to 1994 , followed a complex four-stage probability sampling scheme designed to represent the entire United States civilian non-institutionalized population over the age of 2 months ${ }^{36}$. Mexican Americans were oversampled to comprise nearly a third of the survey population, and Mexican American ethnicity was self-reported. Participation in the survey included interviews conducted at the subjects' homes in either English or Spanish, followed by a physical examination, a diet and health interview, and diagnostic tests conducted at a mobile examination centre (MEC).

\section{Disease status}

Individuals between the ages of 20 and 74 years were invited to receive a gallbladder ultrasound examination at the MEC using real-time ultrasonography administered by a certified abdominal ultrasound technician. Cases were defined as subjects with gallstones if opacity was viewed in the gallbladder producing a distal shadow in both the supine and the left decubitus positions, according to commonly used criteria ${ }^{34}$. If the gallbladder was not seen by ultrasonography and a right upper quadrant or epigastric scar was observed, it was concluded that a cholecystectomy, or surgical removal of the gallbladder, had been performed. GBD was defined as either having gallstones or having undergone cholecystectomy. Videotapes of all ultrasound examinations were independently reviewed by radiologists specializing in abdominal ultrasonography. The Kappa statistic ${ }^{37}$ was used to evaluate agreement between technicians' and radiologists' diagnoses and was found to be 0.94 .

\section{Dietary intake and other covariates}

Household interviews included a food frequency questionnaire in which respondents estimated the number of times per day, week or month that they ate each of 60 food items during the previous month. Individuals were also asked about the type of milk they usually drank; with the replacement of one generic milk item with four more specific milk items, there was a total of 63 food items from the food frequency questionnaire. A list of these foods is provided in the Appendix. The food list used for the questionnaire is similar to those used in previous NHANES, with several food items added to capture the intake of important sources of nutrients related to cancer, cardiovascular disease and osteoporosis. The food list was additionally modified to include important foods consumed by non-Hispanic whites, African Americans and Mexican Americans, who made up the three major subgroups of the NHANES III study population. Information on foods consumed by these subgroups was based on data from NHANES II and the Hispanic Health and Nutrition Examination Survey (HHANES). Food frequency responses were used to identify patterns of food intake, which were then related to GBD status.

Other interview information was obtained prior to ultrasound examination. Regular breakfast consumption was used as a proxy for length of overnight fast, and attempted weight loss during the past 12 months was used as a proxy for history of dieting. Subjects were classified as ever-smokers if they reported smoking at least 100 cigarettes during their entire lifetime. Body mass index (BMI) was calculated using measurements made at the MEC. Information on reproductive factors for women was obtained in a separate questionnaire administered at the MEC and included current pregnancy, total number of live born children, birth control pill use and oral oestrogen or female hormone use.

\section{Identification of food intake patterns}

We used principal components analysis ${ }^{38}$ to identify eating patterns underlying the intake of foods in Mexican American women and men (SAS version 6.11, SAS Institute, Cary, NC). We conducted analyses in women and men separately. Individuals were randomly placed into one of two equally sized groups, or split samples, and analyses were conducted in the two split samples for each sex in order to confirm the reliability of results. For each of the four groups, we constructed a matrix of correlations among the frequency of consumption per month for the 63 food items, and the correlation matrix was entered in the principal components analysis.

The number of meaningful components to retain from the total number extracted depended chiefly on the examination of scree plots and on interpretability of the components $^{39}$. Four components consistently emerged in both split samples of women, and three consistently emerged in men; thus, four components in women and three in men were retained for rotation. Since orthogonal and oblique rotations produced similar results, we present the results from the orthogonal rotation only.

Although in general the same major patterns emerged in both samples in women and men, slightly different sets of foods loaded highly on each component across split 
samples. To reconcile results from the split samples for each sex, we identified sets of 'definite' and 'possible' foods to attach to each pattern. 'Definite' food items were those with loadings of at least 0.30 in both split samples, but whose loadings on other components were substantially less. 'Possible' foods were those whose loadings were above 0.20 for the given component in both split samples but less for other components. The decision to include or exclude these 'possible' foods from the set of foods describing each pattern was based on their effects on the component's coefficient alpha ${ }^{40}$, used to evaluate internal consistency for each component retained. To finalize the set of foods to attach to each pattern, we first calculated a coefficient alpha based on both 'definite' and 'possible' foods together. If removal of a 'possible' food from the set resulted in a higher coefficient alpha for one or both split samples, then we excluded that food from the pattern description.

We calculated factor scores for each pattern by taking the unweighted sum of standardized frequencies of intake for each food associated with the pattern. A factor score was calculated for each dietary pattern for each individual and was taken to represent the individual's level of intake for the pattern.

Over $95 \%$ of the study participants responded to all 63 items in the food frequency questionnaire. Three individuals who missed at least 54 items were excluded from these analyses. If individuals were missing responses on individual foods in any given pattern of food intake identified by principal components analysis, we imputed a value for the missing food by taking the average standardized frequency of all other non-missing foods in that pattern. This was necessary in 40 instances in 38 women, and in 90 instances in 80 men. One man was excluded from analyses on the traditional food intake pattern because there were not enough non-missing responses for other food items in that pattern to impute values for missing foods.

\section{Data analysis}

We categorized factor scores into quartiles and calculated prevalence odds ratios PORs as measures of association between each food intake pattern and $\mathrm{GBD}^{41}$. PORs and their 95\%CI were estimated using unconditional logistic regression modelling ${ }^{41}$ and were weighted using SUDAAN software (SUDAAN version 7.0, Research Triangle Institute, Research Triangle Park, NC) to take into account the complex sampling design.

PORs were adjusted for age by including age in the model as a continuous variable. They were further adjusted for other potential confounders, including regular breakfast consumption, attempted weight loss last year and smoking history. In women, additional variables evaluated as potential confounders were number of live births, ever use of birth control pills, ever use of oral oestrogen or female hormones, and current pregnancy status.

We also investigated the effect of controlling for BMI as a possible intermediate in the pathway between some dietary patterns and GBD. Because the log odds ratio for GBD did not increase in a linear fashion with increasing BMI in men, BMI was entered into logistic regression models as a nominal variable, with BMI categorized as $<25,>25-29$.9, and $\geqslant 30 \mathrm{~kg} \mathrm{~m}^{-2}$, corresponding with categories of normal range BMI, grade 1 overweight, and grades 2 and 3 overweight, respectively, as suggested by a World Health Organization (WHO) Expert Committee ${ }^{42}$. We also left BMI as a continuous variable in models for women since the log odds ratio for GBD increased linearly with increasing BMI in women. However, because results were similar regardless of how BMI was coded, results are presented only for the WHO method of categorization for both sexes.

We estimated PORs for selected individual foods from the food frequency questionnaire that have been associated with GBD previously. We estimated intake of simple sugars from sweetened beverages and from desserts. Monthly frequency of intake of sweetened beverages was estimated by summing together responses for regular sodas and Kool-Aid-type drinks, such as Hi-C, Tang and Hawaiian Punch. Because including coffee and tea did not materially affect results, we present findings without these two beverages. Desserts included summed responses for chocolate and pastries, and alcohol included summed responses for beer, wine and liquor. We created categories of frequency of intake per month that were equivalent to the following categories: never, less than once a week, 1-2 times per week, 2-6 times per week, every day and more than once a day. Categories were subsequently collapsed depending on the frequency distribution for each food item to ensure an adequate number of subjects within each group.

We conducted tests for linear trend in the log odds ratio of categories of intake for each food pattern by fitting a logistic model with age and an ordinal variable representing the median factor score for each pattern quartile.

We performed additional analyses using more limited case definitions by: (i) excluding cholecystectomy cases, assuming that cases with gallstones at ultrasound were less likely to alter their diets as a result of disease diagnosis or symptoms; and (ii) additionally excluding gallstone cases who had been told by a doctor that they had gallstones. These exclusions served to limit cases to those least likely to be aware of their disease status and, hence, least likely to alter their dietary habits as a result of disease.

\section{Results}

Of 5551 Mexican Americans aged 20-74 years selected to take part in NHANES III, $4641(83.6 \%)-2306$ women and 2335 men - were interviewed at home and invited to receive a gallbladder ultrasound. Characteristics of the study population are shown in Table 1 , and associations between various risk factors and GBD in the population are shown in Table 2. 
Table 1 Characteristics of the Mexican American study population by sex in the third National Health and Nutrition Examination Survey, 1988-94

\begin{tabular}{lcc}
\hline & $\begin{array}{c}\text { Women } \\
(n=2306) * \dagger\end{array}$ & $\begin{array}{c}\text { Men } \\
(n=2335) * \dagger\end{array}$ \\
\hline Mean age (years) & 37.5 & 35.8 \\
GBD (\%) & 22.1 & 5.4 \\
$\quad$ Gallstones & 11.3 & 3.9 \\
$\quad$ Cholecystectomy & 10.8 & 1.5 \\
Country of birth (\%) & & \\
$\quad$ Mexico & 50.8 & 58.5 \\
USA & 48.9 & 40.9 \\
Other & 0.4 & 0.6 \\
Highest grade completed $<12(\%)$ & 56.5 & 59.1 \\
Poverty-income ratio $<1(\%)$ & 37.9 & 32.1 \\
\hline
\end{tabular}

* Numbers may differ because of missing responses for each characteristic. The number missing information for each of the following variables were: GBD, 216 women, 251 men; country of birth, 6 women, 4 men; grade completion, 24 women, 31 men; poverty-income ratio, 286 women, 291 men.

†Means and proportions are weighted to reflect population distribution.

We identified four meaningful intake patterns in women and three similar patterns in men (Table 3). The components retained could explain only a small amount of the variation in food intake in our population; together, the four patterns in women accounted for $19-20 \%$ of the total variance, while the three in men accounted for about $15 \%$. Coefficient alphas for the retained components are also shown in Table 3.

To give an idea of the differences in food intake across quartiles for each pattern, median monthly frequencies of intake of selected foods for each pattern are shown in Fig. 1 for women and Fig. 2 for men. Median frequencies of intake for these foods ranged from zero or once a month in the first quartile, to as high as once every day in the fourth quartile. Mean BMI did not vary substantially by quartile for any of the patterns (data not shown).

There were 2090 women and 2084 men with information on disease status. Because adjustment for other risk factors and for BMI did not appreciably change odds ratio estimates or alter our conclusions, only age-adjusted PORs are presented. None of the patterns of intake appeared to be associated with prevalence of GBD in women (Table 4). In men, the traditional pattern was inversely associated with GBD prevalence: men in the third and fourth quartiles of intake of this pattern were roughly half as likely to have GBD as those in the lowest quartile. Age-adjusted PORs were generally similar when we used the more limited case definitions that excluded cholecystectomy and diagnosed gallstones.

In analyses on individual foods (Table 5), alcohol was inversely related to GBD in both women and men; individuals who drank alcohol more than twice a week during the previous month were about half as likely to have GBD as non-drinkers. There was an inverse association between beans and GBD in men only, and a weak inverse association with desserts in women only.

Table 2 Age-adjusted prevalence odds ratios (POR) and $95 \% \mathrm{Cl}$ for gallbladder disease by levels of covariates in Mexican Americans, by sex: third National Health and Nutrition Examination Survey, 198894

\begin{tabular}{|c|c|c|}
\hline & Women & Men \\
\hline $\begin{array}{l}\mathrm{BMI}\left(\mathrm{kg} \mathrm{m}^{-2}\right) \\
\quad<25 \\
25-29.9 \\
\geqslant 30\end{array}$ & $\begin{array}{l}1.00 \\
1.31(0.89-1.94) \\
2.76(2.09-3.64)\end{array}$ & $\begin{array}{l}1.00 \\
0.82(0.44-1.56) \\
1.24(0.77-1.98)\end{array}$ \\
\hline $\begin{array}{l}\text { Ever smoked }>100 \text { cigarettes* }^{*} \\
\text { Eat breakfast every day* } \\
\text { Tried to lose weight last year* }\end{array}$ & $\begin{array}{l}1.23(0.84-1.82) \\
0.82(0.62-1.07) \\
1.58(1.15-2.19)\end{array}$ & $\begin{array}{l}0.80(0.46-1.40) \\
1.15(0.82-1.63) \\
0.97(0.54-1.74)\end{array}$ \\
\hline $\begin{array}{l}\text { Number of live births } \\
0 \\
1-2 \\
3-4 \\
>4\end{array}$ & $\begin{array}{l}1.00 \\
2.77(1.46-5.27) \\
3.38(1.77-6.45) \\
2.91(1.53-5.54)\end{array}$ & \\
\hline $\begin{array}{l}\text { Currently pregnant } \\
\text { Ever used birth control pills* } \\
\text { Ever used oestrogens or female hormones* }\end{array}$ & $\begin{array}{l}0.56(0.27-1.13) \\
1.30(0.93-1.83) \\
1.03(0.49-2.15)\end{array}$ & \\
\hline
\end{tabular}

*POR for yes vs. no. 
However, no trend could be discerned in men for lower GBD risk with increasing bean consumption. We found no evidence of an association of GBD with intake of sweetened beverages or fish (results not shown). When we limited our case definition to gallstone cases unaware of disease status, results were generally the same, but a positive association emerged between beans and gallstones in women; PORs relative to those eating beans less than once a week were $1.22(0.73,2.03), 1.24(0.75,2.06)$ and $1.58(1.02,2.46)$ for those eating beans $1-2$ times a

Table 3 Food intake patterns identified in Mexican Americans, by sex: third National Health and Nutrition Examination Survey, 1988-94

\begin{tabular}{|c|c|c|c|c|c|}
\hline \multirow[b]{2}{*}{ Pattern } & \multirow[b]{2}{*}{ Food item } & \multicolumn{2}{|c|}{ Women } & \multicolumn{2}{|c|}{ Men } \\
\hline & & $\begin{array}{l}\text { Sample } 1 \\
(n=1178)\end{array}$ & $\begin{array}{l}\text { Sample } 2 \\
(n=1126)\end{array}$ & $\begin{array}{l}\text { Sample } 1 \\
(n=1192)\end{array}$ & $\begin{array}{l}\text { Sample } 2 \\
(n=1142)\end{array}$ \\
\hline \multirow[t]{17}{*}{ High calorie } & Processed meats & 0.58 & 0.54 & 0.46 & 0.56 \\
\hline & Salty snacks & 0.51 & 0.49 & 0.55 & 0.56 \\
\hline & Chocolate & 0.48 & 0.25 & 0.47 & 0.44 \\
\hline & White bread & 0.45 & 0.40 & 0.50 & 0.45 \\
\hline & Pork, ham & 0.44 & 0.48 & 0.25 & 0.38 \\
\hline & Pastries & 0.41 & 0.37 & 0.50 & 0.43 \\
\hline & Beef & 0.40 & 0.50 & 0.42 & 0.46 \\
\hline & Cheese dishes & 0.36 & 0.38 & 0.34 & 0.28 \\
\hline & Soda & 0.34 & 0.41 & 0.35 & 0.40 \\
\hline & Fruit drinks & 0.29 & 0.32 & 0.36 & 0.37 \\
\hline & Flour tortillas & 0.42 & 0.39 & - & - \\
\hline & Potato & - & - & 0.44 & 0.41 \\
\hline & Cheese & - & - & 0.41 & 0.40 \\
\hline & Ice cream & - & - & 0.36 & 0.28 \\
\hline & Dressing & - & - & 0.30 & 0.46 \\
\hline & Pizza & - & - & 0.30 & 0.33 \\
\hline & Butter & - & - & 0.25 & 0.27 \\
\hline Variance explained (\%) & & 7.3 & 7.0 & 4.7 & 4.9 \\
\hline Coefficient alpha & & 0.64 & 0.64 & 0.67 & 0.69 \\
\hline \multirow[t]{18}{*}{ Vegetable } & Carrots & 0.54 & 0.60 & 0.62 & 0.53 \\
\hline & Salad & 0.51 & 0.55 & 0.52 & 0.45 \\
\hline & Broccoli & 0.48 & 0.53 & 0.55 & 0.51 \\
\hline & Greens & 0.45 & 0.42 & 0.38 & 0.34 \\
\hline & Other vegetables & 0.43 & 0.49 & 0.35 & 0.48 \\
\hline & Cauliflower & 0.38 & 0.41 & 0.49 & 0.51 \\
\hline & Other fruits & - & - & 0.48 & 0.24 \\
\hline & Melon & - & - & 0.46 & 0.29 \\
\hline & Citrus fruit & - & - & 0.46 & 0.41 \\
\hline & Yellow fruit & - & - & 0.44 & 0.29 \\
\hline & Soups, stews & - & - & 0.43 & 0.49 \\
\hline & Cabbage & - & - & 0.42 & 0.38 \\
\hline & Other juice & - & - & 0.38 & 0.34 \\
\hline & Citrus juice & - & - & 0.35 & 0.36 \\
\hline & Fish & - & - & 0.33 & 0.35 \\
\hline & Chicken & - & - & 0.31 & 0.27 \\
\hline & Rice & - & - & 0.29 & 0.30 \\
\hline & Shellfish & - & - & 0.28 & 0.34 \\
\hline Variance explained (\%) & & 4.1 & 5.5 & 7.3 & 6.9 \\
\hline Coefficient alpha & & 0.65 & 0.67 & 0.75 & 0.72 \\
\hline \multirow[t]{8}{*}{ Traditional } & Beans & 0.68 & 0.55 & 0.60 & 0.56 \\
\hline & Corn tortillas & 0.52 & 0.57 & 0.55 & 0.57 \\
\hline & Chilli peppers & 0.38 & 0.36 & 0.45 & 0.35 \\
\hline & Whole milk & 0.28 & 0.38 & 0.26 & 0.28 \\
\hline & Organ meats & 0.23 & 0.30 & 0.34 & 0.30 \\
\hline & Low-fat milk & -0.23 & -0.25 & -0.45 & -0.22 \\
\hline & Diet drinks & - & - & -0.39 & -0.37 \\
\hline & Dark bread & - & - & -0.44 & -0.48 \\
\hline Variance explained (\%) & & 2.9 & 4.0 & 4.2 & 4.1 \\
\hline Coefficient alpha & & 0.43 & 0.51 & 0.54 & 0.48 \\
\hline \multirow[t]{5}{*}{ Fruit } & Yellow fruits & 0.52 & 0.54 & - & - \\
\hline & Citrus juice & 0.49 & 0.34 & - & - \\
\hline & Other juices & 0.48 & 0.41 & - & - \\
\hline & Ice cream & 0.44 & 0.40 & - & - \\
\hline & Melon & 0.44 & 0.47 & - & - \\
\hline Variance explained (\%) & & 5.2 & 2.9 & - & - \\
\hline Coefficient alpha & & 0.53 & 0.46 & - & - \\
\hline
\end{tabular}


Table 4 Age-adjusted prevalence odds ratios and $95 \% \mathrm{Cl}$ for gallbladder disease by quartile of food intake pattern in Mexican Americans, by sex: third National Health and Nutrition Examination Survey, 1988-94

\begin{tabular}{lllll}
\hline $\begin{array}{l}\text { Quartile of food } \\
\text { intake pattern }\end{array}$ & \multicolumn{1}{c}{ Vegetable } & High calorie & Traditional & Fruit \\
\hline $\begin{array}{l}\text { Women } \\
1 \text { (low) }\end{array}$ & 1.00 & 1.00 & 1.00 & 1.00 \\
2 & $1.32(0.95-1.82)$ & $1.10(0.83-1.44)$ & $1.14(0.84-1.55)$ & $1.54(1.16-2.03)$ \\
3 & $1.04(0.81-1.35)$ & $1.10(0.75-1.60)$ & $1.01(0.74-1.37)$ & $1.10(0.82-1.48)$ \\
4 (high) & $0.91(0.63-1.29)$ & $0.87(0.60-1.24)$ & $0.81(0.57-1.15)$ & $1.20(0.89-1.61)$ \\
$P$ for trend* & 0.06 & 0.98 & 0.17 & 0.97 \\
Men & & & & 1.00 \\
1 (low) & 1.00 & 1.00 & $0.78(0.44-1.40)$ & \\
2 & $1.04(0.55-1.99)$ & $0.85(0.47-1.56)$ & $0.42(0.21-0.85)$ & \\
3 (high) & $1.61(0.86-3.04)$ & $1.47(0.68-3.21)$ & $0.53(0.28-1.01)$ & \\
$P$ for trend* & $1.28(0.83-1.95)$ & $1.19(0.59-2.41)$ & 0.01 & \\
\hline
\end{tabular}

$* P$ value for trend was obtained for each food intake pattern by including an ordinal variable representing the median factor score for each quartile into the logistic model.

week, 2-6 times a week and at least once a day, respectively. In men, the associations of the traditional intake pattern and alcohol with GBD persisted when both were included in the same model (results not shown).

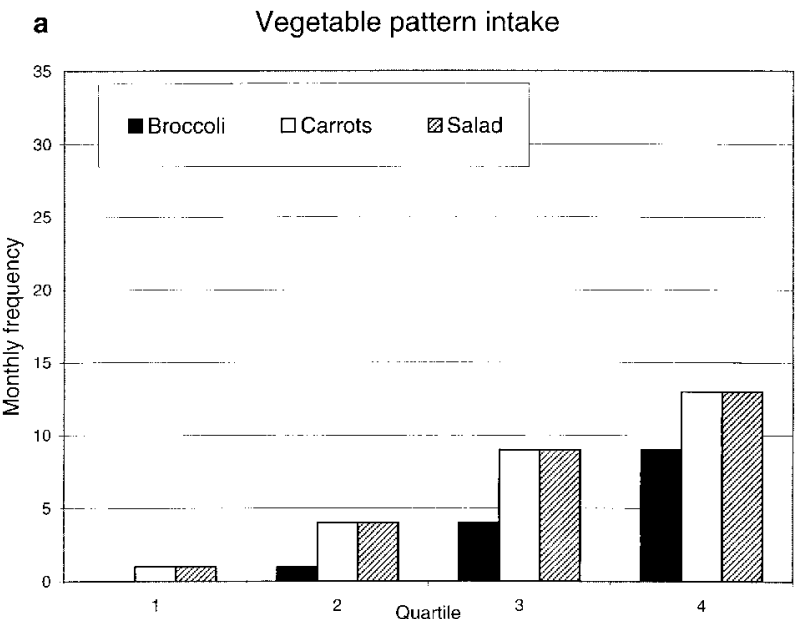

c Traditional food pattern intake

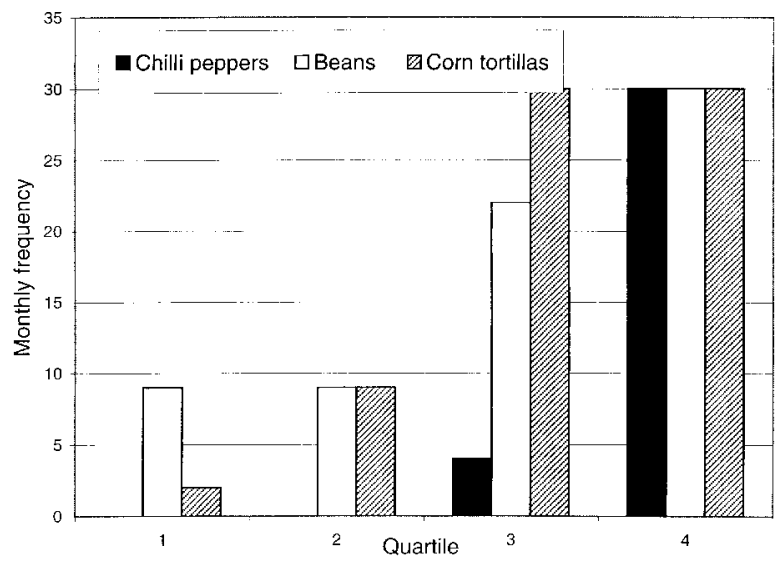

\section{Discussion}

We identified four distinct dietary patterns in women and three in men. None appeared to be associated with GBD



d Fruit pattern intake

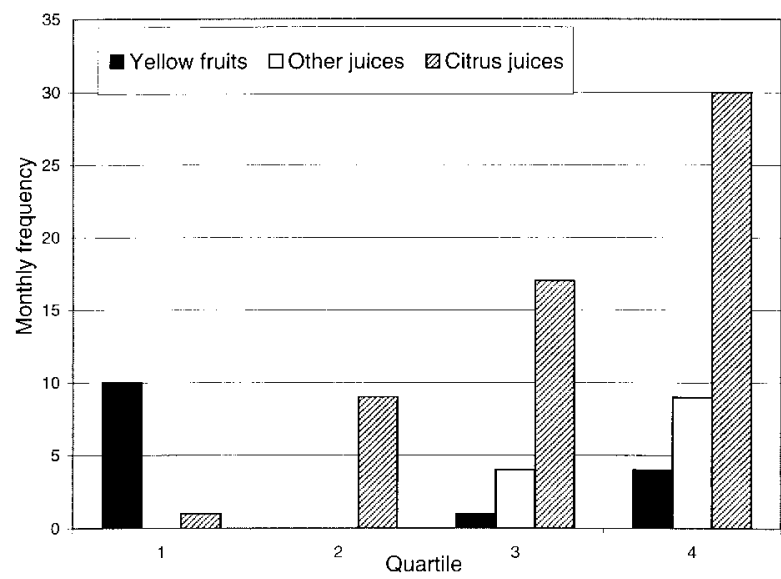

Fig. 1 Median monthly frequency of intake of selected foods by quartile for each food intake pattern in Mexican American women: third National Health and Nutrition Examination Survey, 1988-94 
a Vegetable pattern intake

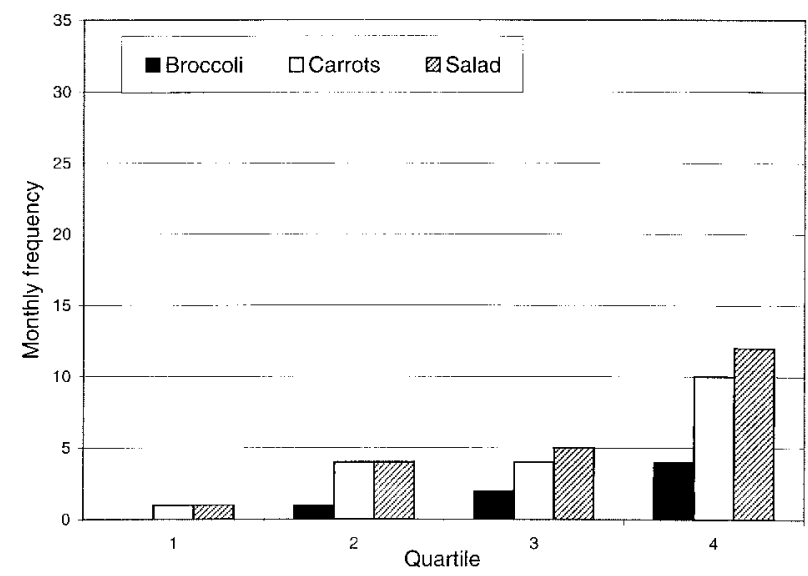

b High-calorie food pattern intake

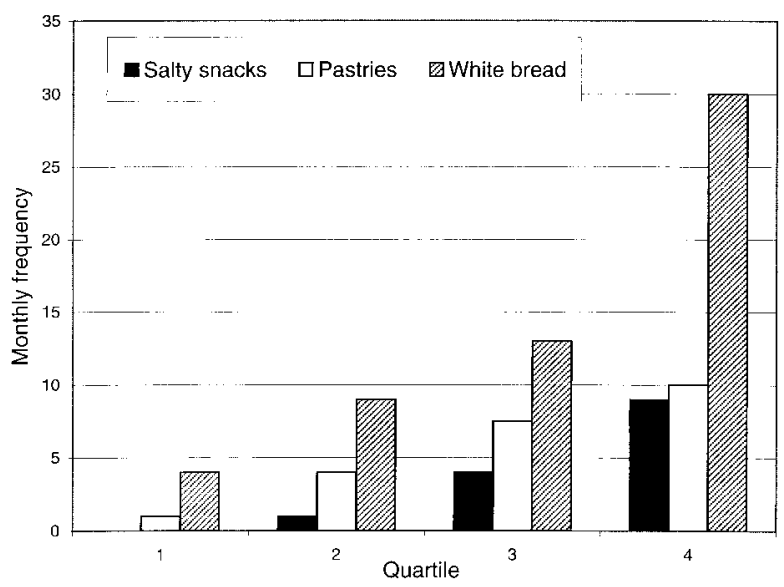

c Traditional food pattern intake

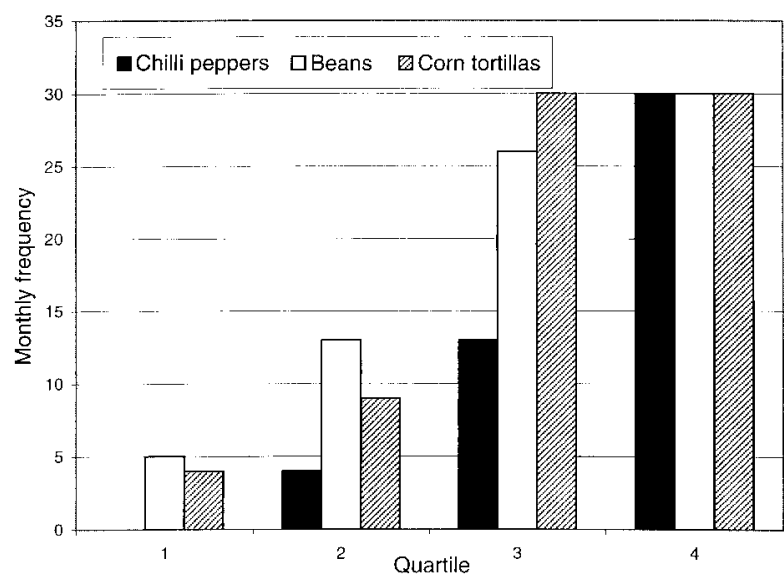

Fig. 2 Median monthly frequency of intake of selected foods by quartile for each food intake pattern in Mexican American men: third National Health and Nutrition Examination Survey, 1988-94

prevalence except the traditional intake pattern in men, which was associated with decreased prevalence of GBD. Among the individual food items that we investigated, intake of beans was inversely associated with GBD in men, and alcohol was inversely associated in both women and men.
Table 5 Age-adjusted prevalence odds ratios and $95 \% \mathrm{Cl}$ for gallbladder disease by levels of intake for specific foods in Mexican Americans, by sex: third National Health and Nutrition Examination Survey, 1988-94

\begin{tabular}{lll}
\hline & \multicolumn{1}{c}{ Women } & \multicolumn{1}{c}{ Men } \\
\hline Alcohol & & \\
Never & 1.00 & 1.00 \\
$<1 /$ week & $0.99(0.59-1.65)$ & $1.24(0.54-2.82)$ \\
$1-2 /$ week & $0.77(0.41-1.43)$ & $0.71(0.42-1.21)$ \\
$>2 /$ week & $0.51(0.29-0.89)$ & $0.59(0.34-1.03)$ \\
$P$ for trend* & 0.02 & 0.04 \\
Beans & & \\
$<1 /$ week & 1.00 & 1.00 \\
$1-2 /$ week & $0.95(0.60-1.49)$ & $0.65(0.33-1.29)$ \\
$2-6 /$ week & $1.13(0.78-1.64)$ & $0.54(0.25-1.16)$ \\
$\geqslant 1 /$ day & $1.05(0.74-1.51)$ & $0.59(0.24-1.44)$ \\
$P$ for trend* & 0.49 & 0.45 \\
Desserts & & \\
$<1 /$ week & 1.00 & 1.00 \\
$1-2 /$ week & $1.04(0.76-1.42)$ & $1.15(0.63-2.12)$ \\
$>2 /$ week & $0.75(0.50-1.12)$ & $1.07(0.56-2.06)$ \\
$P$ for trend* & 0.08 & 0.93 \\
\hline
\end{tabular}

* $P$ value for trend was obtained for each food intake pattern by including an ordinal variable representing the median frequency for each quartile into the logistic model.

Several studies have attempted to identify food intake patterns in different populations using a variety of methods ${ }^{43-54}$. We chose to use principal components analysis to examine food intake patterns, first identifying foods that are correlated with each other or occur together in the diets of our study participants, and then categorizing people according to their level of intake of each set of foods identified. Although principal components analysis has been criticized for defining patterns that may not be reproducible across populations ${ }^{55}$, two patterns identified in the present study, the high-calorie and fruit/vegetable patterns, resembled the 'western' and 'prudent' patterns identified in two recent studies conducted in two separate US populations ${ }^{48,56}$. Hu et al. ${ }^{56}$ found the two patterns to be reasonably reproducible and valid based on dietary data from the Health Professionals Follow-up Study.

Another study looked at dietary patterns defined by principal components analysis in Mexican American women specifically, using data from HHANES ${ }^{46}$. Again, there were similarities among patterns identified in that and the present study. The 'nutrient dense' and 'traditional' patterns identified in the HHANES analysis corresponded with the vegetable and traditional patterns identified in the present study. Our 'high-calorie' pattern appeared to be a composite of the 'transitional' and 'nutrient dilute' patterns identified in that study. Other patterns identified were 'protein-rich', 'high-fat dairy' and 'mixed dishes'. The seven factors extracted in the HHANES analysis explained $59 \%$ of the total variance in frequency of consumption of the food groups. In contrast, the three to four factors extracted in our analyses could explain only $15-20 \%$. The difference in proportion of variance explained arose in part because we extracted fewer factors. More important, however, in the HHANES analysis, 47 foods were 
collapsed into 18 food groups, and there is potentially less unique variance among 18 food groups than among 63 food items, as in our analysis. We chose not to collapse food categories because different individual food items although it may seem to make biological or intuitive sense to group them together - are consumed in different contexts and in different combinations of which we may not be aware a priori. Thus, rather than create groups of potentially dissimilar foods, we chose to use principal components analysis to establish relationships among individual food items empirically.

We are unaware of other studies that have systematically described food intake patterns to evaluate GBD risk, although two studies have found that vegetarians are less likely to have gallstones than non-vegetarians ${ }^{57,58}$. Other studies have looked at the association of GBD with specific foods. Some have observed a positive association with sweet foods ${ }^{19,59-61}$, and inverse associations with fish ${ }^{30,60-62}$ and with beans and pulses ${ }^{17,30,61,63}$. Observed associations for foods may be attributed to specific factors in these foods, or they may represent the effect of other foods with which they are consumed in the diet.

In our study, there was no clear association of GBD with sweetened beverages and desserts or with fish. We found an inverse association with beans in men but no trend, while beans appeared to be associated with higher prevalence in women when we used a more limited case definition. An experimental study in Chilean men suggested that legume intake may increase biliary cholesterol saturation, thereby contributing to gallstone occurrence ${ }^{64}$. Reasons for the discrepant findings regarding legumes are unknown.

Consistent with most previous research, we found an inverse association between alcohol intake and $\mathrm{GBD}^{5,12,14,16,19,20,22-31}$. Moderate alcohol intake may protect against gallstone development through its association with reduced biliary cholesterol saturation and higher serum $\mathrm{HDL}^{7,23}$

It is possible that diet is a more important contributor to GBD in men than in women. While no strong risk factors for GBD have emerged for men, several have been identified in women, including BMI, oral contraceptive and oestrogen use, and parity. In the women in our study population, BMI and number of live births were strongly associated with GBD; these, rather than diet, may be more important determinants of disease in this group.

Importantly, in men, a strong association with traditional intake pattern and GBD was found, while only a limited, non-dose-related association was seen with beans, which is a component of the traditional pattern. Furthermore, it is unclear if the association between the traditional pattern and GBD can be attributed to a single specific component of the diet, such as fibre. In this study population, the traditional food pattern was associated with a lower per cent of kilocalories from total fat, but a higher intake of cholesterol and fibre (data not shown). It is notable, however, that one recent clinical trial found no reduction in gallstone recurrence in individuals given a high-fibre, low-refined-carbohydrate diet ${ }^{65}$. In additional analyses in our study population, we found no major differences in intake between those with and without disease for any single nutrients of a priori interest, including total fat, cholesterol and fibre (data not shown).

Selection bias and selective over- or underreporting are unlikely to have produced the observed inverse association between the traditional intake pattern and GBD. The extent to which the association might be confounded by other potentially confounding factors such as physical activity $^{28,66,67}$ requires further evaluation.

Various features of NHANES III made it more difficult to find an association between intake patterns and disease. The dietary questionnaire used in NHANES III was not designed specifically to measure dietary patterns. Also, aspects of the food frequency questionnaire - for example, random error arising from difficulty in estimating frequency of intake - may have attenuated correlations among foods, leading to imprecise estimation of factor scores. The grouping of dissimilar food items in the NHANES III food frequency questionnaire may also have attenuated correlations among foods, weakening the factor structure of the food items, and contributing to the relatively low coefficient alphas we observed for some of the components. A stronger factor structure might have produced more internally consistent and precisely quantifiable intake patterns.

Furthermore, dietary data were collected at the time of disease ascertainment and may not reflect past intake or intake during the relevant period of disease development. Differential change in consumption patterns over time may explain the failure to find an association for some dietary patterns. However, limiting cases to those presumably unaware of their gallstones did not alter our conclusions. Also, the proportion of non-cholecystectomy gallstone cases reporting abdominal pain during the previous year was similar to that in the non-case population (data not shown), suggesting that most of them were indeed asymptomatic. Although it is possible that such an approach may limit findings to asymptomatic or less severe cases, we find no reason to expect differences in risk factors for the development of asymptomatic as opposed to symptom-associated gallstones.

We found a traditional intake pattern to be inversely associated with GBD prevalence, but only among Mexican American men. This pattern proved at least as, if not more, strongly associated with GBD as did examination of individual foods. That none of the food intake patterns identified in women were associated with GBD may suggest that other lifestyle factors are more important determinants of GBD, such as BMI and reproductive factors. The purpose of this research was not to uncover aetiology but to determine if food intake patterns as a means of characterizing dietary intake are associated with disease. Our findings add to a growing literature showing 
that dietary intake does not have to be characterized in terms of its individual (single nutrient) components to be informative on diet-disease associations. Indeed, if findings are to be used for preventive rather than aetiological purposes, complete understanding of the specific actions and contributions of individual components may not be necessary - an idea recognized in recent clinical trials ${ }^{68,69}$. Measurement of dietary intake patterns in observational studies can provide potentially useful and relevant information on dietary influences on disease risk, but methods to do so require further development and validation.

\section{Acknowledgements}

The authors thank Dr Matthew P. Longnecker for his useful comments on this manuscript. This research was supported in part by grants T32 DK07634 and P30 DK34987 from the National Institutes of Health.

\section{References}

1 Muhrbeck O, Ahlberg J. Prevalence of gallstone disease in a Swedish population. Scand.J. Gastroenterol. 1995; 30: 1125-8.

2 Rhomberg HP, Judmair G, Lochs A. How common are gall stones? BMJ 1984; 289: 1002.

3 Attili AF, Carulli N, Roda E, et al. Prevalence data of the Multicenter Italian Study on Cholelithiasis (MICOL). Am. J. Epidemiol. 1995; 141: 158-65.

4 Hanis CL, Hewett-Emmett D, Kubrusly LF, et al. An ultrasound survey of gallbladder disease among Mexican Americans in Starr County, Texas: frequencies and risk factors. Ethnicity Dis. 1993; 3: 32-43.

5 Maurer KR, Everhart JE, Ezzati TM, et al. Prevalence of gallstone disease in Hispanic populations in the United States. Gastroenterology 1989; 96: 487-92.

6 Sampliner RE, Bennett PH, Comess LJ, Rose RA, Burch TA. Gallbladder disease in Pima Indians: demonstration of high prevalence and early onset by cholecystography. $N$. Engl.J. Med. 1970; 283: 1358-64.

7 Hayes KC, Livingston A, Trautwein EA. Dietary impact on biliary lipids and gallstones. Annu. Rev. Nutr. 1992; 12: 299326.

8 Heaton KW. The role of diet in the aetiology of cholelithiasis. In: Capocaccia L, Ricci G, Angelico F, Angelico M, Attili AF, eds. Epidemiology and Prevention of Gallstone Disease. Lancaster: MTP Press, 1984

9 Heaton KW. The epidemiology of gallstones and suggested aetiology. Clin. Gastroenterol. 1973; 2: 67-83.

10 Nakayama F, Miyake H. Changing state of gallstone disease in Japan. Am. J. Surg. 1970; 120: 794-9.

11 Reid SM, Fullmer SD, Pettigrew KD, et al. Nutrient intake of Pima Indian women: relationships to diabetes mellitus and gallbladder disease. Am. J. Clin. Nutr. 1971; 24: 1281-9.

12 Scragg KR, Calvert GD, Oliver JR. Plasma lipids and insulin in gall stone disease: a case-control study. BMJ 1984; 289: 521-5.

13 Pixley F, Mann J. Dietary factors in the aetiology of gall stones: a case-control study. Gut 1988; 29: 1511-15.

14 Jørgensen T, Jørgensen LM. Gallstones and diet in a Danish population. Scand. J. Gastroenterol. 1989; 24: 821-6.

15 Diehl AK, Haffner SM, Knapp JA, Hazuda HP, Stern MP. Dietary intake and the prevalence of gallbladder disease in Mexican Americans. Gastroenterology 1989; 97: 1527-33.
16 Maclure KM, Hayes KC, Colditz GA, Stampfer MJ, Speizer FE, Willett WC. Weight, diet, and the risk of symptomatic gallstones in middle-aged women. N. Engl. J. Med. 1989; 321: 563-9.

17 Maclure KM, Hayes KC, Colditz GA, Stampfer MJ, Willett WC. Dietary predictors of symptom-associated gallstones in middle-aged women. Am. J. Clin. Nutr. 1990; 52: 916-22.

18 Sichieri R, Everhart JE, Roth H. A prospective study of hospitalization with gallstone disease among women: role of dietary factors, fasting period, and dieting. Am. J. Public Health 1991; 81: 880-4.

19 Moerman CJ, Smeets FWM, Kromhout D. Dietary risk factors for clinically diagnosed gallstones in middle-aged men. Ann. Epidemiol. 1994; 4: 248-54.

20 Sama C, Morselli Labate AM, Cornia GL, et al. Dietary habit and cholelithiasis: results of an epidemiological study. Hepatology 1985; 5: 984.

21 Alessandrini A, Busco MA, Gatti E, Rossi PA. Dietary fibres and cholesterol gallstones: a case control study. Ital. J. Gastroenterol. 1982; 14: 156-8.

22 Diehl AK, Haffner SM, Hazuda HP, Stern MP. Coronary risk factors and clinical gallbladder disease: an approach to the prevention of gallstones? Am. J. Public Health 1987; 77: 841-5.

23 La Vecchia C, Decarli A, Ferraroni M, Negri E. Alcohol drinking and prevalence of self-reported gallstone disease in the 1983 Italian National Health Survey. Epidemiology 1994; 5: 533-6.

24 Kono S, Shinchi K, Ikeda N, Yanai F, Imanishi K. Prevalence of gallstone disease in relation to smoking, alcohol use, obesity, and glucose tolerance: a study of self-defense officials in Japan. Am. J. Epidemiol. 1992; 136: 787-94.

25 Kono S, Shinchi K, Todoroki I, et al. Gallstone disease among Japanese men in relation to obesity, glucose intolerance, exercise, alcohol use, and smoking. Scand. $J$. Gastroenterol. 1995; 30: 372-6.

26 Friedman GD, Kannel WB, Dawber TR. The epidemiology of gallbladder disease: observations in the Framingham study. J. Chron. Dis. 1966; 19: 273-92.

27 Klatsky AL, Friedman GD, Siegelaub AB. Alcohol use and cardiovascular disease: the Kaiser-Permanente experience. Circulation 1981; 64 (Suppl. III): 32-41.

28 Kato I, Nomura A, Stemmermann GN, Chyou PH. Prospective study of clinical gallbladder disease and its association with obesity, physical activity, and other factors. Dig. Dis. Sci. 1992; 37: 784-90.

29 Wheeler M, Hills LL, Laby B. Cholelithiasis: a clinical and dietary survey. Gut 1970; 11: 430-7.

30 Pastides H, Tzonou A, Trichopoulos D, et al. A case-control study of the relationship between smoking, diet, and gallbladder disease. Arch. Intern. Med. 1990; 150: 140912.

31 La Vecchia C, Negri E, D'Avanzo B, Franceschi S, Boyle P. Risk factors for gallstone disease requiring surgery. Int. J. Epidemiol. 1991; 20: 209-15.

32 Randall E, Marshall JR, Graham S, Brasure J. Patterns in food use and their associations with nutrient intakes. Am.J. Clin. Nutr. 1990; 52: 739-45.

33 US Department of Health and Human Services (DHHS), National Center for Health Statistics. Third National Health and Nutrition Examination Survey, 1988-1994, NHANES III Household Adult Data File (CD-ROM). Public Use Data File Documentation No. 77560. Hyattsville, MD: Centers for Disease Control and Prevention, 1996.

34 US Department of Health and Human Services (DHHS), National Center for Health Statistics. Third National Health and Nutrition Examination Survey, 1988-1994, NHANES III Examination Data File (CD-ROM). Public Use Data File Documentation No. 76200. Hyattsville, MD: Centers for Disease Control and Prevention, 1996. 
35 Everhart JE, Khare M, Hill M, Maurer KR. Prevalence and ethnic differences in gallbladder disease in the United States. Gastroenterology 1999; 117: 632-9.

36 US Department of Health and Human Services (DHHS), National Center for Health Statistics. Plan and Operation of the Third National Health and Nutrition Examination Survey, 1988-94. Vital and Health Statistics, Series 1(32). Hyattsville, MD: Centers for Disease Control and Prevention, 1994.

37 Fleiss JL. Statistical Methods for Rates and Proportions. New York: John Wiley and Sons, 1981.

38 Kleinbaum DG, Kupper LL, Muller KE. Applied Regression Analysis and Other Multivariable Methods. Belmont, CA: Duxbury Press, 1988.

39 Kline P. An Easy Guide to Factor Analysis. New York: Routledge, 1994.

40 Cronbach LJ. Coefficient alpha and the internal structure of tests. Psychometrika 1951; 16: 297-334.

41 Kleinbaum DG, Kupper LL, Morgenstern H. Epidemiologic Research: Principles and Quantitative Methods. New York: Van Nostrand Reinhold, 1982.

42 WHO Expert Committee. Physical status: the use and interpretation of anthropometry. Report of a WHO Expert Committee. WHO Tech. Rep. Ser. 1995; 854: 1-452.

43 Schwerin HS, Stanton JL, Riley AM Jr, et al. Food eating patterns and health: a reexamination of the Ten-State and HANES I surveys. Am. J. Clin. Nutr. 1981; 34: 568-80.

44 Nicklas TA, Webber LS, Thompson B, Berenson GS. A multivariate model for assessing eating patterns and their relationship to cardiovascular risk factors: the Bogalusa Heart Study. Am. J. Clin. Nutr. 1989; 49: 1320-7.

45 Randall E, Marshall JR, Graham S, Brasure J. High-risk health behaviors associated with various dietary patterns. Nutr. Cancer 1991; 16: 135-51.

46 Wolff $\mathrm{CB}$, Wolff HK. Maternal eating patterns and birth weight of Mexican American infants. Nutr. Health 1995; 10: 121-34.

47 Gittelsohn J, Wolever TMS, Harris SB, Harris-Giraldo R, Hanley AJG, Zinman B. Specific patterns of food consumption and preparation are associated with diabetes and obesity in a native Canadian community. J. Nutr. 1998; 128: $541-7$.

48 Slattery M, Boucher K, Caan B, et al. Eating patterns and risk of colon cancer. Am. J. Epidemiol. 1998; 148: 4-16.

49 Akin JS, Guilkey DK, Popkin BM, Fanelli MT. Cluster analysis of food consumption patterns of older Americans. J. Am. Diet. Assoc. 1986; 86: 616-24.

50 Hulshof KFAM, Wedel M, Löwik MRH, et al. Clustering of dietary variables and other lifestyle factors (Dutch Nutritional Surveillance System). J. Epidemiol. Community Health 1992; 46: 417-24.

51 Tucker KL, Dallal GE, Rush D. Dietary patterns of elderly Boston-area residents defined by cluster analysis. J. Am. Diet. Assoc. 1992; 92: 1487-91.

52 Margetts BM, Campbell NA, Armstrong BK. Summarizing dietary patterns using multivariate analysis. J. Hum. Nutr. 1981; 35: 281-6.

53 Patterson RE, Haines PS, Popkin BM. Diet quality index: capturing a multidimensional behavior. J. Am. Diet. Assoc. 1994; 94: 57-64.

54 Randall E, Nichaman MZ, Contant CF Jr. Diet diversity and nutrient intake. J. Am. Diet. Assoc. 1985; 85: 830-6.

55 Martinez M, Marshall J, Sechrest L. Invited commentary: factor analysis and the search for objectivity. Am. J. Epidemiol. 1998; 148: 17-19.

56 Hu F, Rimm E, Smith-Warner S, et al. Reproducibility and validity of dietary patterns assessed with a food-frequency questionnaire. Am. J. Clin. Nutr. 1999; 69: 243-9.

57 Pixley F, Wilson D, McPherson K, Mann J. Effect of vegetarianism on development of gall stones in women. BMJ 1985; 291: 11-12.
58 Kratzer W, Kächele V, Mason RA, et al. Gallstone prevalence in relation to smoking, alcohol, coffee consumption, and nutrition. Scand. J. Gastroenterol. 1997; 32: 953-8.

59 Scragg KR, McMichael AJ, Baghurst PA. Diet, alcohol, and relative weight in gall stone disease: a case-control study. BMJ 1984; 288: 1113-19.

60 Ortega RM, Fernández-Azuela M, Encinas-Sotillos A, Andrés P, López-Sobaler AM. Differences in diet and food habits between patients with gallstones and controls. J. Am. Coll. Nutr. 1997; 16: 88-95.

61 Attili AF. Dietary habits and cholelithiasis. In: Capocaccia L, Ricci G, Angelico F, Angelico M, Attili AF, eds. Epidemiology and Prevention of Gallstone Disease. Lancaster, UK: MTP Press, 1984; 175-81.

62 Misciagna G, Leoci C, Guerra V, et al. Epidemiology of cholelithiasis in southern Italy. Eur. J. Gastroenterol. Hepatol. 1996; 8: 585-93.

63 Linos AD, Daras V, Linos DA, Kekis V, Tsoukas MM, Golematis V. Dietary and other risk factors in the aetiology of cholelithiasis: a case control study. HPB Surg. 1989; 1: 221-7.

64 Nervi F, Covarrubias C, Bravo P, et al. Influence of legume intake on biliary lipids and cholesterol saturation in young Chilean men. Gastroenterology 1989; 96: 825-30.

65 Hood KA, Gleeson D, Ruppin DC, Dowling RH. Gall stone recurrence and its prevention: the British/Belgian Gall Stone Study Group's post-dissolution trial. Gut 1993; 9: 1277-88.

66 Jørgensen T. Gall stones in a Danish population. Relation to weight, physical activity, smoking, coffee consumption, and diabetes mellitus. Gut 1989; 30: 528-34.

67 Leitzmann MF, Giovannucci E, Rimm EB, Stampfer MJ, Willett WC. Physical activity and the risk of gallstone disease in men. Ann. Intern. Med. 1998; 128: 415-25.

68 Appel L, Moore T, Obarzanek E, et al. A clinical trial of the effects of dietary patterns on blood pressure. N. Engl.J. Med. 1997; 336: 1117-24.

69 Lanza E, Schatzkin A, Ballard-Barbash R, et al. The Polyp Prevention Trial II: dietary intervention program and participant baseline dietary characteristics. Cancer Epidemiol. Biomarkers Prev. 1996; 5: 385-92.

\section{Appendix}

The 63 foods included in the principal components analysis were as follows.

\section{Milk and milk products}

1. Chocolate milk or hot cocoa.

2. Whole/regular milk.

3. Low-fat or $1 \%$ milk.

4. Skimmed/non-fat milk.

5. Buttermilk, evaporated milk or other milk.

6. Yogurt or frozen yogurt.

7. Ice cream, ice milk or milkshakes.

8. Cheese, all types.

9. Pizza, calzone or lasagna.

10. Cheese dishes (such as macaroni and cheese or cheese quesadillas).

\section{Main dishes, meat, fish, chicken and eggs}

11. Vegetable-containing stew or soup.

12. Spaghetti and pasta with tomato sauce.

13. Bacon, sausage or luncheon meats.

14. Liver and other organ meats. 
15. Beef.

16. Pork and ham.

17. Shrimp, clams, oysters, crab or lobster.

18. Fish, including fillets, fish sticks, fish sandwiches and tuna fish.

19. Chicken.

20. Eggs.

\section{Fruit and fruit juices}

21. Orange, grapefruit or tangerine juice.

22. Other fruit juices (such as grape or apple juice or fruit nectars).

23. Citrus fruits.

24. Melons.

25. Peaches, nectarines, apricots, guava, mango or papaya.

26. Other fruits (such as apples, bananas or pears).

\section{Vegetables}

27. Carrots or vegetable mixtures with carrots.

28. Broccoli.

29. Brussels sprouts or cauliflower.

30. White potatoes.

31. Sweet potatoes, yams or orange squash.

32. Tomatoes, including fresh and stewed tomatoes, tomato juice and salsa.

33. Spinach, greens, collards or kale.

34. Tossed salad.

35. Cabbage, coleslaw or sauerkraut.

36. Hot red chilli peppers.

37. Peppers including green, red and yellow peppers.

38. Other vegetables (such as green beans, corn or peas).

Beans, nuts, cereals and grain products

39. Beans, lentils or chickpeas/garbanzos.
40. Peanuts, peanut butter and other types of nuts or seeds.

41. All-Bran, All-Bran Extra Fiber, 100\% Bran or Fiber One.

42. Total, Product 19, Most or Just Right.

43. All other cold cereals (such as corn flakes, Cheerios or presweetened cereals).

44. Cooked and hot cereals.

45. White bread, rolls, bagels, biscuits, English muffins or crackers.

46. Dark breads and rolls.

47. Corn bread, corn muffins or corn tortillas.

48. Flour tortillas.

49. Rice.

50. Salted snacks (such as potato chips, taco chips or salted pretzels).

\section{Desserts, sweets and beverages}

51. Cakes, cookies, brownies, pies, doughnuts or pastries.

52. Chocolate candy and fudge.

53. Hi-C, Tang, Hawaiian Punch, Kool-Aid and other drinks with added vitamin $C$.

54. Diet colas, diet sodas and diet drinks such as Crystal Light.

55. Regular colas and sodas, not diet.

56. Regular coffee with caffeine.

57. Regular tea with caffeine

58. Beer and lite beer.

59. Wine, wine coolers, sangria and champagne.

60. Hard liquor (such as tequila, gin, whiskey and liqueurs), either alone or mixed.

\section{Fats}

61. Margarine.

62. Butter.

63. Oil and vinegar, mayonnaise and salad dressings. 